\title{
A New Method for Measuring Pistoning in Lower Limb Prosthetic
}

H. Gholizadeh1, N.A. Abu Osman1, Á.G. Lúðvíksdóttir2, M. Kamyab3, A. Eshraghi1, S. Aliı, and W.A.B. Wan Abası

1 Department of Biomedical Engineering, Faculty of Engineering, University of Malaya,

Kuala Lumpur, Malaysia

${ }_{2}$ Clinical Research, R\&D, Össur Head Office, Reykjavík, Iceland

3 Orthotics \& Prosthetics Department, Faculty of Rehabilitation Sciences,

Tehran University of Medical Sciences, Tehran, Iran

INTRODUCTION

The lower limb prosthesis's efficiency is mainly guaranteed

by its optimal suspension method in order to secure the socket

to the amputee's stump. Suspension and fitness in residual

limb prosthesis have main role in comfort and prosthetic

function [1,2].The most important factor mentioned by the

amputees is the fit of their prosthesis and suspension [3].

Pistoning or vertical movement of the residual limb inside the prosthetic socket is said to be one of the major indications of evaluating suspension method of lower limb prosthesis [4].

Prosthetic fitting has been said to be correlated with pistoning [5]. Thus, measuring the pistoning would be helpful in determining the optimal prosthetic fit. Several methods have been used to measure pistoning movement occurring in different levels. The movement can be between the hard socket and the liner, between the liner and the skin, and between the skin and the bone $[5,6]$. Radiological methods include roentgenology $[7,8]$, cineradiography $[9,10]$, and roentgen stereo photogrammetric analysis [6]. Ultrasonic methods or transducer are also used to record the pistoning $[11,12,13]$. However, since these methods required complicated devices and settings, and X-ray expose is not ethical for the subjects, these studies mostly have been limited to laboratory and were not used clinically. 
The objective of this study was to introduce and assess a new method for measuring pistoning within the socket, designed and developed in-house at Össur for the first time.

\section{Methodology}

\section{A. Subjects}

Three male unilateral transtibial amputees (mean, 42 years old), that used Pattelar tendon bearing socket (PTB) for the last 3 years with silicone liner and shuttle lock, with mobility grade K3, based on American Academy of Orthotists \& Prosthetists, participated in this study. Ethical approval was granted from the University of Malaya Medical Centre (UMMC) Ethics Committee. In this study, we tested pistoning movement in these subjects with the new method. The subjects were required to complete five static trials consist of five different static conditions, including single limb support on prosthetic limb (full weight bearing), non weight bearing, and three different axial loading conditions. Loads of 30, 60 and $90 \mathrm{~N}$ were added to the prosthetic foot.

\section{B. Technique for Measuring Pistoning (Developed by}

Össur)

To identify any pistoning movement inside a prosthetic socket the following equipments are required:

-good high quality measuring tape,

$-3,6$ and $9 \mathrm{~kg}$ loads,

-high resolution camera

-Two reference rulers (with an accurate and known length) on the lateral side of the limb and the socket - to be used as a reference when measuring the displacement on the photos (the ruler attached to the limb is used as a measuring reference for $\mathrm{A}$ and $\mathrm{B}$, and the ruler attached to the socket is used as a measuring references for $\mathrm{C}$ and D) 
-Black ink markers on the following positions (Fig 1):

Greater Trochanter (A), proximal lateral end of liner (B),

proximal lateral end of socket (C), distal end of socket (D)

In the 5 conditions below, we used the measuring tape to

measure following four distances: $\mathrm{AD}, \mathrm{AC}, \mathrm{AB}$, and $\mathrm{BD}$

(Fig 1).

For each condition we took a photo from a fixed point

using a photo stand. The photo was taken so that the

markers (and the reference ruler) could be seen clearly, and

was not at an angle from the photo stand.

Conditions:

1. Amputee standing full weight bearing on prosthesis (all

the body weight on the prosthesis) - This was the baseline measure.

2. Amputee standing with no weight on prosthesis with the leg straight (e.g. on stairs with the sound leg on the step and prosthesis suspending freely)

3. Applying 30 Newton force in the longitudinal axis of the prosthesis with the leg straight

4. Applying 60 Newton force in the longitudinal axis of the prosthesis with the leg straight

5. Applying 90 Newton force in the longitudinal axis of the prosthesis with the leg straight.

\section{Calculating Pistoning Movements}

The measurement when the user stood full weight bearing on prosthesis was used as a baseline (AD standing, $\mathrm{AC}$ standing, $\mathrm{AB}$ standing, $\mathrm{BD}$ standing).Then the other four conditions were compared to the baseline to identify any pistoning movement. The $\triangle \mathrm{AD}$ displacement was calculated as follows:

1. $\triangle \mathrm{AD}$ (no weight $)=\mathrm{AD}$ no weight $-\mathrm{AD}$ standing

2. $\triangle \mathrm{AD}(30 \mathrm{~N})=\mathrm{AD} 30$ Newton $-\mathrm{AD}$ standing

3. $\triangle \mathrm{AD}(60 \mathrm{~N})=\mathrm{AD} 60$ Newton $-\mathrm{AD}$ standing

4. $\Delta \mathrm{AD}(90 \mathrm{~N})=\mathrm{AD} 90$ Newton $-\mathrm{AD}$ standing 
The calculations on previous step were repeated for AC,

$\mathrm{AB}$ and $\mathrm{BD}$. We compared the displacement for the three

distances $(\mathrm{AD}, \mathrm{AC}$ and $\mathrm{BD})$ and found the mean

displacement. In order to find the errors of measurements, the differences in displacement between the measures were compared. Ideally the displacement should have been the same for the three distances, $\mathrm{AD}, \mathrm{AC}$ and $\mathrm{AB}+\mathrm{BD}$.

Deviations represented errors of measurement.

The photos were used to validate the tape measurements by measuring the distance between the markers on the photos and the reference rulers were employed to calculate the real distance between the markers. Finally, we compared those results to the tape measures.

Full text is available at :

http://download.springer.com/static/pdf/504/chp\%253A10.1007\%252F978-3-642-21729-

6 177.pdf?auth $66=1393724134$ c9c685562defb784352c426b49cf3ca1\&ext=.pdf

http://link.springer.com/chapter/10.1007/978-3-642-21729-6_177 